\title{
A Review of Herbal Medicines for Nausea and Vomiting of Pregnancy in Traditional Persian Medicine
}

\author{
Shahrbanoo Abdolhosseini ${ }^{1}$, Fataneh Hashem Dabaghian ${ }^{2}$, Mitra Mehrabani $^{3}$, Roshanak Mokaberinejad ${ }^{4}$ \\ ${ }^{1}$ Department of Traditional Medicine, School of Traditional Medicine, Kerman University of Medical Sciences, Kerman, Iran \\ ${ }^{2}$ Community Medicine Specialist, Research Institute for Islamic \& Complementary Medicine, Iran University of Medical Sciences, \\ Tehran, Iran \\ ${ }^{3} \mathrm{Herbal}$ and Traditional Medicines Research Center, Kerman University of Medical Sciences, Kerman, Iran \\ ${ }^{4}$ Department of Traditional Medicine, School of Traditional Medicine, Shahid Beheshti University of Medical Sciences, Tehran, Iran
}

\begin{abstract}
Nausea and vomiting of pregnancy (NVP) is one of the prevalent pregnancy complaints. This study was conducted to review the medicinal plants mentioned in Traditional Persian Medicine (TPM) for the treatment of NVP. A literature research was conducted on a number of main references of TPM, including the books of al-Qanun fi al-Teb, Zakhireye Kharazmshahi, Tadbir-al-Habali al-Atfal al-Sabiban and Makhzan-al-Adviah. Then, medicinal plants mentioned in TPM for treatment of NVP were determined and searched in electronic databases, including PubMed and Google Scholar to find studies that confirmed their efficacy. The search terms were "vomiting" or "nausea" or "emesis" and "pregnancy" and the name of each herb. Data were collected for the years 1990-2016. The findings included 10 plants. Citrus limon (Lemon), Citrus medica L. (Citron), Cydonia oblonga (Quince), Elletaria cardamomum (Cardamom), Mentha spicata L. (Spearmint), Menatha piperita (Mint), Myristica fragrans Houtt (Nutmeg), Pistacia lentiscus Linn. (Mastic), Punica granatum L. (Pomegranate), Malus domestica Borkh (Apple), and Piper cubeba L. are the most recommended medications for NVP. There is evidence in human studies for some of these medicinal plants (Mentha Piperita L., Citrus limon, Elletaria cardamom, and Cydonia oblonga Mill). The other mentioned herbs have not been evaluated during pregnancy. There is limited evidence to safely recommend these plants for NVP. Although some human studies have suggested the antiemetic effects of TPM remedies, their safety is not sufficiently documented in modern literature. Scientific studies on these medicinal plants during pregnancy are warranted to determine their safety. [GMJ.2017;6(4):281-90] DOI: 10.22086/gmj.v0i0.809
\end{abstract}

Keywords: Nausea; Vomiting; Pregnancy; Traditional Medicine; Morning Sickness

Introduction

$\mathrm{T}$ he prevalence of nausea is reported to be $50-80 \%$ and $50 \%$ for vomiting and retch-

\section{GMJ}

@2017 Galen Medical Journal

Tel/Fax: +98 7136474503

PO Box 7193616563

Email:info@gmj.ir ing during pregnancy [1]. Nausea and vomiting begin in the first trimester, at about 6-8 weeks' gestation, peaking at about 9 weeks' gestation and subsiding at about 12 weeks.

\footnotetext{
Correspondence to:

Roshanak Mokaberinejad, Department of Traditional Medicine, School of Traditional Medicine, Shahid Beheshti University of Medical Sciences, Tehran, Iran Telephone Number: +982188773521

Email Address : rmokaberi@gmail.com
} 
Only a minority of women have symptoms after 20 weeks' gestation. Loss of working days, decreased quality of life, difficulty in child birth preparation, and decline in energy and fatigue are considerable stresses that women with nausea and vomiting of pregnancy (NVP) experience [2]. The pathophysiology is a combination of genetic, endocrine, gastrointestinal, environmental, and psychosocial factors. Although the exact causes of NVP are unknown, the level of human chorionic gonadotropin (hCG), placental prostaglandins, serotonin, estrogen and progesterone, size of the placental mass, thyroid dysfunction, increased leptin levels, immune system dysregulation, Helicobacter pylori infection, and gastrointestinal dysmotility may be involved [3]. The current anti-emetic drugs to control NVP can be classified as vitamins (B6, B1), anti-dopaminergic drugs, serotonin antagonists, antihistamines, anti-cholinergic drugs, promotility agents, and corticosteroids [4]. The side effects of current anti-emetic drugs have turned attention to the use of traditional medicines [5]. Some of these side effects include tardive dyskinesia with metoclopramide, headache, diarrhea, constipation, fatigue with ondansetron, sedation, and extrapyramidal symptoms with promethazine [3]. Traditional remedies are used by the people of a region for many years, indicating their efficacy and safety [6]. Traditional Persian Medicine (TPM), as one of the complementary/alternative medicine (CAM) methods, tries to offer simple and available recommendations for health maintenance and treatment of diseases in different groups of people (e.g., pregnant women). Medicinal plants are the most commonly used components of TPM medications [7]. Because of concerns related to the consumption of drugs in early pregnancy, natural remedies could be considered in this regard. The aim of the present study was to review the efficacy of medicinal herbs claimed to be effective in TPM for NVP.

\section{Search strategies}

This literature research was conducted to investigate some important Persian medical and pharmaceutical manuscripts from the ninth to the eighteenth century CE. Medicinal herbs used for the treatment of NVP were extracted from the most famous TPM books including the Canon (al-Qanun fi al-Teb) of Avicenna (Ibn Sina, 980-1032 AD)[8], Zakhireye Kharazmshahi of Jorjani (Hussain ibn Muhammad ibn Mahmoud ibn Ahmad Hussaini Jorjani, 10421137 AD)[9], Tadbir-al-Habali al- Atfal alSabiban of Albaladi (Ahmad ibn muhammad Albaladi 990 AD), and Makhzan-al-Adviah of Aghili Khorasani (Mir Muhammad Hussain ibn Muhammad Hadi Aghili Khorasani 1843 AD). The words "Ghessyan (nausea), Ghey (vomiting), Tahavo (Retch) and Taghalobe naphs (permanent nausea), Tadbir Al-Havamel or Al-Habali or Abestan or Bardari (Pregnancy)" were searched in traditional Persian books mentioned above. These books are specified as traditional Persian references in medicine and pharmacy and are now used as references for the Iranian PhD program in traditional medicine. Moreover, side effects of these herbal medicines and their safety in pregnancy were considered through a search in Physician's Desk Reference (PDR) [10] and Botanical Safety [11]. The scientific names of the reported herbal drugs were confirmed using textbooks such as Popular Medicinal Plants of Iran [12]. PubMed, Google Scholar, Iran medex, and SID (the last two are Iranian databases) were searched using all scientific names of plants separately from 1990 to 2016. The inclusion criteria of the selected articles were any clinical and animal evidence of the efficacy and safety on treatment of NVP. The publications without available full texts, case reports, and older studies (before 1990) were excluded from the study. The literature search revealed 829 articles, of which 798 were excluded due to irrelevance, being repetitive, and lack of eligibility (Figure-1). Then, 31 articles were included after retrieving their full texts and methods. Three CTs met our inclusion criteria; their key data are listed in Table-1. The search terms were "vomiting" or "nausea" or "emesis" or" anti-emetic" and "pregnancy" or "pregnant" in the title and abstract, and the scientific name, common name, and Persian and traditional names of the above-mentioned herbs in the whole text. The included clinical articles were reviewed to extract the scientific name of the 
plant, medicinal part, study design, number of patients, and duration of treatment (Table-1).

\section{Results}

The medicinal herbs mentioned for the management of NVP in TPM and all evidence confirming their efficacy are described individually. Citrus limon (Lemon), Citrus medica L. (Citron), Cydonia oblonga mill (Quince), Elletaria cardamomum (Cardamom), Mentha spicata L. (Spearmint), Mentha piperta L. (Mint), Myristica fragrans Houtt (Nutmeg), Pistacia lentiscus Linn. (Mastic), Punica granatum L. (Pomegranate), Malus domestica Borkh (Apple), and Piper cubeba $L$ are the most commonly recommended medications for treatment of NVP (Table-1) [13-15]). There is evidence of efficacy for some of these medicinal plants (Mentha Piperita L., Citrus limon, Elletaria cardamom) in human studies [16-18] (Table-2).

\section{Citrus limon (Lemon)}

The lemon is a plant of the family Rutaceae [19]. It is known as "Limoo" and has been used as an efficacious remedy for NVP in TPM [20]. It is said to be cold and dry in nature. Lemon contains volatile oils, citric acid, flavonoids [10]. In a randomized clinical trial on 100 pregnant women, lemon essential oil and placebo were given to the intervention and control groups respectively to inhale as soon as they felt nausea, and the PUQE24 (24-hour Pregnancy Unique Quantification of Emesis) was used to assess them. The result was a statistically significant difference between the two groups in the mean score of the fourth day $(\mathrm{P}=0.017$ and $\mathrm{P}=0.039$, respectively) [16]. Citrus Limon could be administered as a supplement to enhance the efficacy of some antibacterial therapies (anti H. pylori) that are part of antiulcer treatment [19]. Citrus limon has been used as natural antiemetic [5]. No health hazards or side effects have been reported following the proper administration of designated therapeutic dosages [10].

\section{Citrus medica L (Citron)}

Citrus medica $L$ is a plant of the family Rutaceae [21]. It is said to be cold and wet in nature [15]. Citrus medica L, known as "Utroj" in TPM, has been used for treatment of NVP $[14,20]$. There is little information on the safety of Citrus medica fruit concentrated extract in pregnancy. To the best of our knowledge, no human studies have evaluated its effects on nausea.

Table 1. Clinical Studies On Plants Used for Treatment of NVP Mentioned in TPM

\begin{tabular}{|c|c|c|c|c|c|}
\hline Scientific name & $\begin{array}{l}\text { Medicinal } \\
\text { part }\end{array}$ & $\begin{array}{l}\text { number of } \\
\text { patients, }\end{array}$ & Type of study & $\begin{array}{l}\text { Treatment } \\
\text { duration }\end{array}$ & Outcome \\
\hline Citrus limon & $\begin{array}{l}\text { Lemon } \\
\text { essentials oil }\end{array}$ & 100 & $\begin{array}{l}\text { Randomised, } \\
\text { Double-blind } \\
\text { clinical trial } \\
\text { study }\end{array}$ & 5 days & $\begin{array}{l}\text { nausea and vomiting } \\
\text { intensity }\end{array}$ \\
\hline $\begin{array}{l}\text { Elletaria } \\
\text { Cardamomum }\end{array}$ & $\begin{array}{l}\text { Cardamom } \\
\text { powder }\end{array}$ & 120 & $\begin{array}{l}\text { Randomised, } \\
\text { double-blind } \\
\text { clinical trial } \\
\text { study }\end{array}$ & 4 days & severity of NVP \\
\hline Mentha piperita $\mathrm{L}$ & Mint oil & 67 & $\begin{array}{l}\text { Block- } \\
\text { randomized } \\
\text { method }\end{array}$ & 18 days & severity of NVP \\
\hline $\begin{array}{l}\text { Cydonia Oblonga } \\
\text { Mill }\end{array}$ & $\begin{array}{l}\text { Syrup of } \\
\text { Cydonia } \\
\text { oblonga } \\
\text { (quince) fruit }\end{array}$ & 60 & $\begin{array}{l}\text { Randomised, } \\
\text { clinical trial } \\
\text { study, not } \\
\text { blinded }\end{array}$ & 1 week & \\
\hline
\end{tabular}




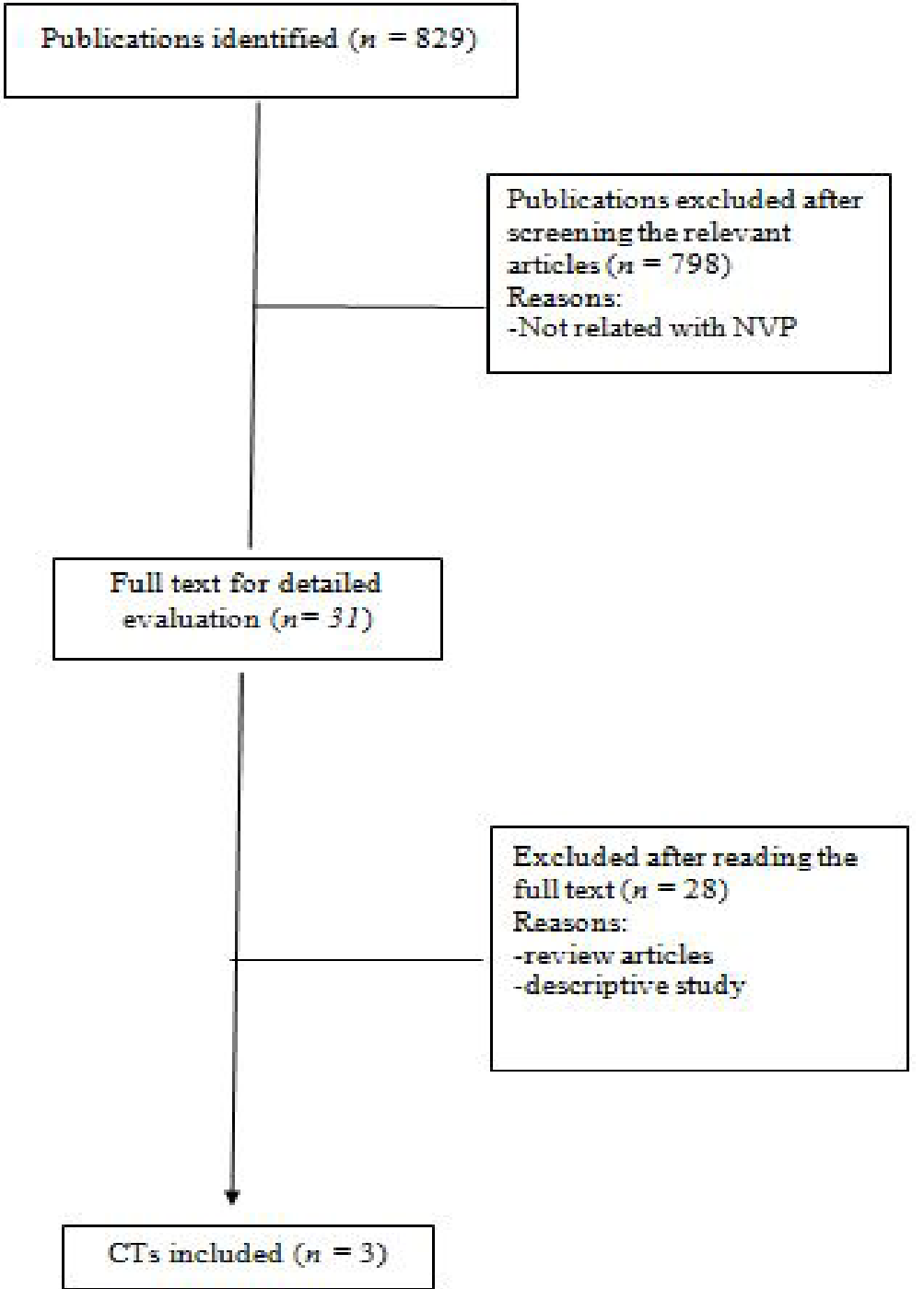

Figure 1- The process of including and excluding studies

3. Cydonia oblonga Mill (Quince)

The quince is a plant of the family Rosaceae [22]. Cydonia oblonga, known as "Beh", is another natural product used in TPM for treatment of NVP [14, 23, 13]. Persian physicians believed that roasted Cydonia oblonga Mill (Quince) was useful in treating nausea in pregnancy [20]. In addition, it protects the fetus from abortion and is used as an appetizer [15] . It is said to be wet and balanced in warm and cold in nature [15]. A clinical trial was carried out in Tehran, Iran on the effectiveness of Cydonia oblonga (quince) syrup for treatment of NVP. The results showed significantly decreased NVP in the group receiving quince syrup $[24,1]$. No health risks or side effects are reported following the proper administration of designated therapeutic dosages [10].

\section{Elletaria cardamom (Cardamom)}

Cardamom is a member of the family Zingiberaceae [12]. Cardamom (Elletaria cardamomum), known as "Hil" or "Hel", has been used in TPM as a stomach tonic and for treatment of digestive complaints and NVP [20, 15]. It is said to be warm and dry in nature [15]. In a study by Pradier et al, a trial of a mixture of three essential oils (Zingiber offcinale, Elletaria cardamomum, and Artemisia dracunculus) in the treatment of postopera- 
tive nausea and vomiting showed that $75 \%$ of cases had a favorable outcome [25]. A double blind randomized clinical trial was performed on 120 pregnant women and capsules containing $500 \mathrm{mg}$ cardamom powder and placebo were administered three times a day half an hour before meals. The PUQE24h was used to evaluate the outcome. The frequency and duration of nausea and the frequency of vomiting significantly decreased in the cardamom powder group $(\mathrm{P}<0.0001)$ [18]. A randomized trial of aromatherapy with patients who reported nausea in the post anesthesia care unit showed that the number of antiemetic medications requested was significantly reduced after aromatherapy with ginger or a blend of the essential oils of ginger, spearmint, peppermint, and cardamom versus saline [26].

\section{Mentha spicata L (Spearmint) and Mentha piperta L (Mint)}

Mint is a plant in the family Lamiaceae [12]. The leaves of mint known as "Na, na" have also been used as an effective drug in the treatment of NVP [14, 13, 23]. It is said to be warm and dry in nature [15]. In a double blind RCT, the effect of aromatherapy with pure mint essential oil versus placebo was evaluated in 60 pregnant women with NVP. For 4 consecutive nights, before sleep, a bowel of water containing 4 drops of pure mint essential oil was placed on the floor near the beds of subjects in the case group while 4 drops of normal saline was used in the control group. The Visual Analog Scale (VAS) was used for assessment. The result showed a decreasing trend (especially in 4th night) in the mint and an increasing trend in the control group. The severity of nausea within 7 days after the intervention had a decreasing trend in both groups; however, the intensity was lower in the mint than saline group but the difference was not significant $(\mathrm{P}=0.14)$ [17]. In a randomized double-blind clinical trial, 200 patients with chemotherapy-induced nausea and vomiting (CINV) were randomly assigned into four groups to receive $M$. spicata or M. piperita. The treatment and placebo groups received essential oils of $M$. spicata, M.piperita, or a placebo, while the control group continued with their previous antiemet- ic regimen. The patients received their normal antiemetic regimen plus spearmint and peppermint capsules (containing two drops of each essential oil and filled with sugar) every four hours. The capsules were administered 30 minutes before the patients received their chemotherapy treatment, again four hours after the first capsule and finally, four hours later at home. It was concluded that there was a significant reduction in the intensity and number of emetic events in the first 24 hours with M. spicata and M. piperita in both treatment groups $(\mathrm{P}<0.05)$ when compared with the control group [10]. Due to the highly concentrated nature of peppermint leaf essential oil, until further safety data is available, internal use during pregnancy should only be under the supervision of a qualified healthcare practitioner [11]. No teratogenic effects of the compound menthol were observed in mice fed $190 \mathrm{mg} / \mathrm{kg}$, rats fed $220 \mathrm{mg} / \mathrm{kg}$, hamsters fed $400 \mathrm{mg} / \mathrm{kg}$, or rabbits fed $430 \mathrm{mg} / \mathrm{kg}$ [11].

\section{Myristica fragrans Houtt (Nutmeg)}

Nutmeg is a plant of the family Myristicaceae [12]. Nutmeg (myristica fragrans), known as "joze bavva", has been used in TPM as a digester, stomach tonic, and antiemetic [15] and for the treatment of NVP [20]. Nutmeg has been used as a carminative, antiemetic, spasmolytic, and anti-inflammatory agent. Moreover, nutmeg has been used for flatulence, diarrhea, nausea, and vomiting [27]. The activities of Myristica fragrans Houtt. seed on H. pylori - induced gastritis in albino rats have been proved [28]. Nutmeg has been used by many women to induce menstruation or abortion, although the literature suggests that nutmeg is not efficacious as an abortifacient [11]. An increase in maternal and fetal heart rate was observed in a pregnant woman who consumed cookies containing an excessive amount of nutmeg. The baby was delivered healthy at term [11]. Animal studies have provided conflicting results, with no adverse effects of the essential oil at doses up to 400 $\mathrm{mg} / \mathrm{kg}$ in rabbits but some abnormalities in rats who administered $300 \mathrm{mg} / \mathrm{kg}$ of nutmeg [11]. An animal study indicated that after giving of mace to lactating mice, physiological effects were observed on both mothers and 
nursing offspring. Thus, its use is not recommended during pregnancy except under the supervision of a qualified healthcare practitioner [11]. No health hazards or side effects are reported following the proper administration of designated therapeutic dosages [10]. To the best of our knowledge, no human studies have evaluated its effects on nausea yet.

\section{Pistacia lentiscus Linn. (Mastic)}

Oleogum resin of Pistacia lentiscus (P. lentiscus) known as "Mastaki" is an efficacious remedy for the treatment of NVP in TPM [14, 20]. It is a resin obtained from the mastic tree, a plant of the family Anacardiaceeae[12]. The medicinal part is the resin. Resins and volatile oils are the components of the mastic tree [10]. In TPM, It is said to be hot and dry in nature [15]. According to the Persian literature, Pistacia lentiscus Linn. relieves gastric inflammation, increases appetite, and is a carminative $[29,15]$. Mastic gum is effective in eradication of H. pylori infection both in vitro and in vivo [30]. No health hazards or side effects are known to the proper administration of designated therapeutic dosages [10]. We found no human studies evaluating its effects on NVP.

\section{Punica granatum L. (Pomegranate)}

The omegranate is a plant of the family Lythraceae [31]. Punica granatum $L$. is known as"Anar" [15]. It is said to be cold and wet in nature. One way to treat NVP in TPM is keeping pomegranate seeds and mint in the mouth $[23,13]$. One clinical trial evaluated the effects of pomegranate and spearmint syrup on NVP [32]. In TPM, pomegranate sauce is used to alleviate nausea [15]. A small number of studies have reported that pomegranate can treat H. pylori infection [33]. No health hazards are reported following the proper administration of designated therapeutic dosages [10].

\section{Malus domestica Borkh (Apple)}

The apple is a plant of the family Rosaceae. It is known as "Tofah" in TPM [15]. The apple has been used in TPM as an appetizer, stomach tonic, and antiemetic, and also for the treatment of NVP [14]. No human studies have evaluated its effects on NVP.

\section{Piper cubeba L. (Cubeb)}

Piper cubeba L. (PICL), a plant in the family Piperaceae, is a carminative, stomach tonic, and antiseptic [34]. Piper cubeba L., known as "kobabeh", is another natural product used in TPM for NVP [20]. It is said to be warm and dry in nature [15]. The constituents of this fruit (alkaloids, glycosides, tannins, and flavonoids) are known to possess potent antioxidant activities and can be used as natural antioxidants [35]. There is no information on the safety of cubeb during pregnancy [11]. No health hazards or side effects have been reported following the proper administration of therapeutic dosage [10]. No human studies have evaluated its effects on NVP.

\section{Discussion}

The etiology of NVP in TPM can be due to effusion and accumulation of inappropriate substances in the stomach and stomach weakness is one of the factors of this etiology. Treatment consists of removing inappropriate substances from the stomach and decreasing their production as well as stomach strengthening [36]. Masters of TPM have always paid attention to the role of nutrition in preventing and treating diseases. For treating nausea in pregnancy, it is recommended to eat food that are light and easy to digest, apply lifestyle modifications, and use some medicinal plants and their preparations [37]. Astringent (Ghabiz) agents, which have the ability to tan the stomach and preserve its tonicity, are one of the treatments for stomach weakness [38]. Punica granatum L. (pomegranate), Cydonia oblonga mill (quince), and Pistacia lentiscus Linn. ( mastic) are examples of astringent medicines that have been repeatedly mentioned in TPM resources for their effect on stomach tanning [15]. Fragmenting (Moghattia), stubbing (Mohallil), and tendering (Mollatif) agents are necessary for removing soft waste materials around the stomach villi [38] and are found in medicinal plants such as Citrus limon (lemon), Mentha spicata L.(spearmint), and Mentha piperta L. (mint)[15]. Removing excess humidity and gas from the 
stomach with some herbal drugs such as Mentha spicata L. (spearmint), and Mentha piperta L. (mint) strengthens the stomach. [38, 15]. Sour (Hamiz) products such as Citrus limon (lemon) are good appetizers in TPM resources that are used to remove thick humors from the stomach, strengthen the stomach, and prevent vomiting [38]. Some euphoric (Mofarrih) agents such as Malus domestica Borkh (apple) and Elletaria cardamomum (cardamom) can strengthen the whole body including the stomach because of their good smell [15, 38]. Although the safety and the mechanism of action of herbal products have always been a matter of concern, attention has been paid to traditional medical systems and herbal medicines because of their few side effects and increasing failure of current drugs [39, 40]. In this study, 10 medicinal plants belonging to 8 families used as antiemetic drugs for NVP in TPM were evaluated. These medicinal plants were assessed from the perspective of traditional and herbal medicine and new studies in this field were reviewed. The main limitation of this study is the lack of relevant studies in databases. There were only four studies on pregnant women that reported the safety of Mentha piperita L (mint), Citrus limon (lemon), Elletaria cardamom (car- damom), and Cydonia oblonga mill (quince). Long-term use of traditional medicines may indicate their efficacy, but it is recommended to conduct scientific studies to confirndnm their efficacy and safety [6]. Scientific studies on these medicinal plants during pregnancy are required to determine their safety.

\section{Conclusion}

Iranian philosophers and scientists have taken rational steps based on the observations. They believed that three basic steps, i.e. lifestyle modification, nutrition and medicinal herbs, had great effects on NVP treatment. Therefore, this study can provide valuable information on the clinical use of herbal medicines in NVP and prepares the ground to investigate their potential medicinal use.

\section{Acknowledgements}

This research is part of the ongoing $\mathrm{PhD}$ thesis of Dr. Shahrbanoo Abdolhosseini at the School of Traditional Medicine, Kerman University of Medical Sciences.

\section{Conflict of Interest}

We declare that we have no conflict of interest.

Table 2. Medicinal Plants Used for Treatment of NVP Mentioned in TPM

\begin{tabular}{lll}
\hline Scientific name & Family & TPM name \\
\hline Citrus limon & Rutaceae & Limoo \\
\hline Citrus medica L. & Rutaceae & Utroj \\
\hline Cydonia oblonga Mill & Rosaceae & Beh, Safarjal \\
\hline Ellataria cardamomum & Zingiberaceae & Hil \\
\hline Mentha piperita, M spicata L. & Lamiaceae & Na na \\
\hline Myristica fragrans Houtt & Myristicaceae & Jose bavva \\
\hline Piper cubeba L. & Piperaceae. & Kobabeh \\
\hline Pistacia lentiscus L. & Anacardiaceae & Mastaki \\
\hline Punica granatum L. & Lythraceae & Anar \\
\hline Malus domestica Borkh & Rosaceae & Tofah \\
\hline
\end{tabular}


1. Matthews A, Haas DM, O’Mathúna DP, Dowswell T, Doyle M. Interventions for nausea and vomiting in early pregnancy. Cochrane Database Syst Rev. 2014;3.

2. Davis MP, RN. Nausea and Vomiting of Pregnancy: An Evidence-based Review. J Perinat Neonatal Nurs. 2004;18(4):312-28

3. Herrell HE. Nausea and vomiting of pregnancy. Am Fam Physician. 2014;89(12):965-70.

4. Thomas B, Rouf PVA, Al-Hail M, al Saad D, Tharannum A. Medication used in Nausea and Vomiting of Pregnancy-A Review of Safety and Efficacy. Gynecology \& Obstetrics. 2015.

5. 5. Anderka M, Mitchell AA, Louik C, Werler MM, Hernández-Diaz S, Rasmussen SA. Medications used to treat nausea and vomiting of pregnancy and the risk of selected birth defects. Birth Defects Res A Clin Mol Teratol. 2012;94(1):22-30.

6. World Health Organization. National policy on traditional medicine and regulation of herbal medicines: Report of a WHO global survey.

7. Hashem Dabaghian F, Taghavi Shirazi M, Amini Behbahani F, Shojaee A. Interventions of Iranian Traditional Medicine for Constipation During Pregnancy. Jmp 2015; 1(53):58-68.

8. Zargaran A, Mehdizadeh A, Zarshenas MM, Mohagheghzadeh A. Avicenna (980-1037 AD). J Neurol. 2012;259(2):389-90.

9. Zarshenas MM, Zargaran A, Abolhassanzadeh Z, Vessal K. Jorjani (1042-1137). J Neurol. 2012:1-2.

10. Fleming T. PDR for herbal medicines. USA: Thomson health care Inc. 2000: 87, 235, 461,476,508, 547,605, 626, 709.

11. 11. Gardner Z, McGuffin M, Botanical Safety; Second Edition, CRC Press; 2013: 232, 328, 562, 569, 588, 663, 718

12. Amin G. Popular Medicinal Plant of Iran.
Tehran: Tehran University of Medical Sciences. 2005: 124, 216, 260, 262. .

13. Arzani M. Mufarrih al-qulub. Tehran, Almaee publications. 2012: 860.

14. Albaladi A. Tadbir-al-Habali,al- Atfal, al-Sabiban. Baghdad, Dar Al-Rashid pub. 1980: 151.

15. Aghili Shirazi MH. Makhzan-al-advia( Persian). Tehran: Tehran University of Medical Sciences; 2011: 122, 260,302. 415-16, 458, 604, 652, 669, 713, 743, 773.

16. Safajou F, Shahnazi M, Nazemiyeh

$\mathrm{H}$. The effect of lemon inhalation aromatherapy on nausea and vomiting of pregnancy: a double-blinded, randomized, controlled clinical trial. Iran Red Crescent Med J. 2014;16(3).

17. 17 . Pasha H, Behmanesh F, Mohsenzadeh F, Hajahmadi M, Moghadamnia AA.

Study of the effect of mint oil on nausea and vomiting during pregnancy. Iran Red Crescent Med J. 2012;14(11):727.

18. ozgholy g, gharayagh zandi $\mathrm{m}$, nazem ekbatani n, allavi h, moattar f. Cardamom powder effect on nausea and vomiting during pregnancy. complementary Medicine Journal. 2015;5(1):1065-76.

19. Rozza AL, de Mello Moraes T, Kushima $\mathrm{H}$, Tanimoto A, Marques MOM, Bauab TM, et al. Gastroprotective mechanisms of Citrus lemon (Rutaceae) essential oil and its majority compounds limonene and $\beta$-pinene: involvement of heat-shock protein-70, vasoactive intestinal peptide, glutathione, sulfhydryl compounds, nitric oxide and prostaglandin E 2. Chem Biol Interact. 2011;189(1):82-9.

20. 20 . Jorjani, L., Zakhireh Kharazmshahi, Qom: Institute for natural medicine; Vol: 2; 2012: 940.

21. Moraes TM, Rozza AL, Kushima H, 
Pellizzon CH, Rocha LRM, Hiruma-Lima CA. Healing actions of essential oils from Citrus aurantium and d-limonene in the gastric mucosa: the roles of VEGF, PCNA, and COX-2 in cell proliferation. J Med Food. 2013;16(12):1162-7.

22. Khoubnasabjafari M, Jouyban A. A review of phytochemistry and bioactivity of quince (Cydonia oblonga Mill.). Journal of Medicinal Plants Research. 2011;5(16):3577-94.

23. Aghili Khorasani M. Khulașat alhikmah. Qom: Esmailian publications. 2006,v:2, p: 147.

24. Jafari Dehordi E. Comparison of'Cydonia Oblonga' fruit product with B6 on nausea and vomiting in pregnancy (Doctoral dissertation, Doctorate Thesis]. Tehran, Iran: School of Traditional Medicine, Iran University of Medical Sciences).

25. De Pradier E. A trial of a mixture of three essential oils in the treatment of postoperative nausea and vomiting. International Journal of Aromatherapy. 2006 Dec 31;16(1):15-20.

26. Hunt R, Dienemann J, Norton HJ, Hartley W, Hudgens A, Stern T, et al. Aromatherapy as treatment for postoperative nausea: a randomized trial. Anesthesia \& Analgesia. 2013;117(3):597-604.

27. Zulfiker AH, Ahmed D, Alam MB, Saha MR, Saha SK, Khalil MI, Menon TM, Rana MS. Phenolic content and in vitro antioxidant potential of selected medicinal plants of Bangladesh. Journal of Pharmacy Research Vol. 2011;4(7):19918.

28. Oyedemi TO, Lawal TO, Adeniyi BA. Effect of Myristica fragrans Houtt. Seed (Nutmeg) on Helicobacter pylori induced gastritis in albino rats: in vitro and in vivo studies. International Journal of Biological and Chemical Sciences. 2015;8(4):1355-67.

29. Razi, M., Al-Hawi. Beirot: Al-Hawi Pharma., 1422. Vol. 6. 385.

30. Marone P, Bono L, Leone E, Bona S,
Carretto E, Perversi L. Bactericidal activity of Pistacia lentiscus mastic gum against Helicobacter pylori. J Chemother. 2001;13(6):611-4.

31. Batista ALA, Lins RDAU, de Souza Coelho R, do Nascimento Barbosa D, Belém NM, Celestino FJA. Clinical efficacy analysis of the mouth rinsing with pomegranate and chamomile plant extracts in the gingival bleeding reduction. Complement Ther Clin Pract. 2014;20(1):93-8.

32. Abdolhosseini S, Hashem-Dabaghian F, Mokaberinejad R, Sadeghpour O, Mehrabani M. Effects of Pomegranate and Spearmint Syrup on Nausea and Vomiting During Pregnancy: A Randomized Controlled Clinical Trial. Iranian Red Crescent Medical Journal. 2017.

33. Colombo E, Sangiovanni E, Dell'Agli M. A review on the antiinflammatory activity of pomegranate in the gastrointestinal tract. Evid Based Complement Alternat Med. 2013.

34. Zaidi SFH, Yamada K, Kadowaki M, Usmanghani K, Sugiyama T. Bactericidal activity of medicinal plants, employed for the treatment of gastrointestinal ailments, against Helicobacter pylori. J Ethnopharmacol. 2009;121(2):286-91.

35. Nahak G, Sahu RK. Phytochemical Evaluation and Antioxidant activity of Piper cubeba and Piper nigrum.

36. Aliasl F, Toliyat T, Aliasl J, Minaee M-B. Nausea and vomiting remedies in Iranian Traditional Medicine (ITM). Iran J Public Health. 2015;44(8):1164-5.

37. Jafari-Dehkordi E, Mokaberinejad R, Minaei B, Sohrabvand F, Nazem E, Dabaghian FH, et al. A Review of Pioneer Physicians' Work on Maternal Health in Pregnancy in Ancient Iran; Narrative Systematic Review. Iran J Public Health. 2013;42(12):1340.

38. Jahromi MM, Pasalar M, Afsharypuor 
S, Choopani R, Mosaddegh M, Kamalinejad $\mathrm{M}$ et al. Preventive care for gastrointestinal disorders; role of herbal medicines in traditional persian medicine. Jundishapur J Nat Pharm Prod. 2015;10:4. 39. Sattari M, Dilmaghanizadeh M,
Hamishehkar H, Mashayekhi SO. Selfreported use and attitudes regarding herbal medicine safety during pregnancy in Iran. Jundishapur J Nat Pharm Prod. 2012;7(2):45-9.

40. Yamini EA. Some questions about herbal and traditional medicine. Nurs Midwifery Stud 2014. 3(1.) 